\section{ON THE AUTONOMY OF THE HEART.}

BY GUIDO BELL, M.D.

INDIANA POLIS, IND.

In the last number of the American Journal of Medi. cal Sciences, Prof. I. M. Da Costa has published eight cases of weak heart, where the causation of neurasthenia and organic disorder, as valvular lesion or fatty degeneration had to be excluded.

$\mathrm{He}$ is inclined to attribute this weakness to the influence of the heart ganglia. Notwithstanding, Romberg ${ }^{1}$ in compiling the recent experimental researches on the heart, has proven that the animal heart is active by itself and is regulated only by the sympathetic and pneumogastric nerves.

The heart's action never could be fully explained, neither in normal nor abnormal condition by its innervation. There was a supposition that Remak's ganglia promoted the activity of the heart; but embryologic researches revealed the fact that the heart is active before it is reached by these nerve centers, and, furthermore, that these centers spread out only sensory nerve filaments. Then nerve-cells in the heart muscle were looked for, but in vain.

If a man of high repute and large experience does not accept what seems to be an established law theoretically, it is in order to report all pathologic experiences which may be apt to sustain theory.

This is so much more justifiable in a case where a phenomenon can not be explained, except by assumption of what was found theoretically to be the truth.

In an article of the Cincinnati Lancet-Clinic of Sept. 19, 1891, I have reported three cases where a peculiar noise of the heart was heard at a distance during the shock. The sound was systolic and appeared not immediately after the injury, but later and stronger, according to the severity of the shock, and lasted until the organism revived and both sounds became audible again.

Both my cases recovered. I could not give a satisfactory explanation at that time, but in a paper read before the Marion County Medical Society in Indianapolis, March 28, 1893, I said that the peculiar noise of the heart heard at a distance during the shock can not be explained, unless the autonomy of the heart is accepted.

The heart meets an undue resistance in the collapsed arteries, and not being restrained by its regulating nerves is working excessively, thereby causing the undulations in the heart region visible through the bed-covers, and the sound audible at a distance of fifteen steps.

I also spoke of the following case: On Jan. 4, 1893, I was called to see John M., at 10 o'clock in the evening. I saw the man, who was 63 years old, half an hour later, lying in a bed without any sign of life.

He was walking the floor after an ordinary day's work, apparently well and in his usual way, when he fell backward without stumbling and lay perfectly motionless. This had happened a short time before 10 o'clock. I found him at 10:30 P.M. with eyes half open, pupils moderately dilated, immovable, lids languid, lips cyanotic, cold skin on face and extremities; temperature in axilla below 95 degrees F.; no respiration; different examinations were made; no pulse at the wrist, but the heart was beating regularly, rot much weaker than in life, twenty-one beats

\footnotetext{
1 In Berlin klin. Woch., March 27, 1893.
}

in fifteen seconds. I counted the heart's sounds seven times, and also my own pulse which was eighteen beats in fifteen seconds. The man was dead, notwithstanding the beating heart. I injected one one-hundredth grain of nitro-glycerin hypodermatically. A few minutes after 11 o'clock the heart's action became irregular and soon ceased.

These pathologic phenomena fully approve Romberg's statement of the autonomy of the heart.

Austin Flint in his text-book on "Human Physiology" says: "The heart seems to act without any palpable excitation." But if both experimental researches and clinical experiences forward such strong evidence, it seems not to be immodest to formulate Prof. Flint's assertion more positively by saying: "The heart does act without any palpable excitation."

\section{FACIAL ERYSIPELAS-TREATED WITH EXTERNAL APPLICATIONS OF GUAIACOL.}

BY CHAS. J. WHALEN, M.D.

INSTRUCTOR IN LARYNGOSCOPY, AND CHIEF ASSISTANT TO THE CIINIC FOR DISEASES OF THE NOSE, THROAT AND CHEST, RUSH MEDICAL COLLEGE; CLINICAI, ASSISTANT TO THE CHAIR OF SURGERY, CHICAGO POLYCLINIC.

A review of the latest literature on erysipelas reveals, on the whole, a very unsatisfactory state as regards the treatment, and marked discrepancies exist in the writings of different authors on the subject. On this account $I$ wish to place before you some observations based on a personal experience with this disease, treated by the external application of guaiacol.

Etiology.-Dr. J. M. Anders of Pennsylvania, gives elaborate statistics to prove that debilitating diseases greatly predispose to this disease. The primary cause is the streptococcus erysipelatosis discovered by Fehleisen. Jordan is of the opinion that the specificity of Fehleisen's erysipelococcus is questionable, and that its identity with the streptococcus pyogenes is probable. He has studied this subject carefully with reference to this question, and has drawn from his observation the conclusion: That erysipelas is etiologically not a specific disease; that, as a rule, it is caused by the streptococcus pyogenes, but that it may be provoked also by the staphylococcus pyogenes aureus.

These cocci which are so nearly identical with the streptococcus pyogenes, are found chiefly iu, and spread along the capillary lymphatics of the skin. Recklinghausen and Lukowsky found them in the lymphatic vessels and connective tissue spaces in the structure affected by erysipelas. Fehleisen found cocci in chains constantly present in bits of skin excised from the spreading edge of an erysipelas rash; they lay in the lymphatics chiefly of the superficial part of the corium, never in blood vessels, and only exceptionally in the connective tissue spaces, or in the immediate vicinity of blood vessels.

Erysipelas spreads along the superficial lymphatics, but not necessarily in the direction of the lymph current, which may be temporarily arrested by blocking of the interior of the lymphatics with cocci. As this microbe is non-motile, its transportation in a direction opposite the lymph current can only occur by reproduction.

In the facial form, when no wound is visible, it is 
probable that infection takes place through some small abrasion, though auto-infection may possibly occur, the organism having been previously absorbed through the respiratory or digestive tract. This, however, seems improbable.

As an addition to our knowledge of the effects of guaiacol in the treatment of this disease, I hope that the following may be of interest:

Case 1.-J. E. S., age 30. I saw the patient November 8. He complained of having had tonsillitis two weeks previously, but he had not regained his strength. Three days before I saw him he began to suffer from headache and appeared to have fever in the afternoon. When first seen by me, he was suffering from nausea, headache and constipation. He had a severe chill the preceding day. I found the temperature 103.5 degrees $F$., pulse 100 . I noticed a slight red blush near the lachrymal duct which had every appearance of the beginning facial erysipelas.

I ordered pure guaiacol applied to the affected area and for some distance beyond, in the hope of preventing further extension. The following day the patient claimed that he had experienced instantaneous relief from the application, that his headache shortly afterward disappeared and the fever gradually subsided, so that he was able to sleep for the first time in four nights.

His appearance, however, was much worse than on the preceding day. The rash had spread laterally to the ears, and had extended over the forehead to the border of the scalp. The eyes were completely closed from edema caused by escape of inflammatory exudate into the loose cellular tissue in this region. There was considerable delirium. At 10 A.m. temperature 104 degrees F, pulse 100. Again applied guaiacol with the same satisfaction as before. The nurse fourd it necessary in this case to make three applications daily for the next four days.

Three hours after the application of the guaiacol, the temperature was 97.5 degrees. At 5 P...., 100.5 degrees $F$.

November 11, temperature, 10 A.M., 99 degrees F.; 5 P.M., 100 degrees $\mathrm{F}$.

November 12, temperature, 10 A.M., 98.8 degrees F.; 5 P.M., 99.5 degrees $\mathrm{F}$.

November 13, temperature, 10 A.M., 98.6 degrees F.; 5 P.M., 99 degrees F. Patient discharged cured.

Case 2.-I was called December 16, to see Mrs. S., mother of preceding patient. Had several previous attacks of erysipelas. At the time of my visit she had a temperature of 104.5 degrees F. Complained of intense headache, dry burning skin and constipation. The rash had extended over the entire face, ears and forehead. Bullæe had formed in the ears. I applied the guaiacol as in the preceding case with marked relief of the symptoms. At 1 P.M. temperature 102 degrees F. At 3 P.M. temperature 101 degrees F. At 5 P M., 103 degrees F. Again painted the face, when the fever gradually receded to 101 degrees F. At 8 P.M, December 17, temperature 101 degrees F., pulse 98 . Urine scant and contained albumen. Guaiacol was applied once a day for the four succeeding days.

December 18, temperature 101 degrees F., pulse 96. Albumen still present.

December 19, temperature 100.5 degrees F., pulse 110 .

December 20, temperature 100.8 degrees $F$., pulse 106 .

December 21, temperature 99 degrees F., pulse 80 . Trace only of albumen found in urine. Patient made a slow recovery.

Case 3.-Wrs. H., age 27 ; eruption limited to the face. Bullæ had formed on the cheeks ; considerable edema about the eyes. Patient was slightly delirious. At 9 A.M., temperature 103 degrees F., pulse 100 ; ordered pure guaiacol painted over the face. At 12 M., temperature 100 degrees $F$. At 2 p.M., 99.5 degrees. At 5 P.M., 100.5 degrees. At 8 P.M., 101 degrees, $F$., when the nurse was obliged to paint the face again. Guaiacol was applied twice a day for the five follow. ing days. Temperature ranged from 99.5 to 101.5 degrees F., when convalescence was established. No albumen found in the urine on repeated examinations. Patient was discharged cured on the sixth day.

Another case illustrates even more clearly the good effect of this drug:

I was called February 15 to see Mrs. F., age 40 years. I found that she had an erysipelatous rash covering the entire face, ears and forehead. Bullæ had formed on the cheeks and upper lip. Her temperature was 103 degrees F, pulse
120 ; dry brown tongue, teeth covered with sordes, bowels constipated; had two chills previous to my visit. Ordered hydrargfri chloridum mite and sodii bicarbonas, aa gr. 5 morning and evening for the bowels; and painted the face with pure guaiacol, from which the patient experienced marked relief. On the following day, at the time of my visit the patient was having a decided chill. I at once applied guaiacol and immediately the chill began growing less intense and within five minutes it entirely ceased. This treatment was repeated on subsequent occasions with the same happy results. Each chill being aborted by the guaiacol applied externally over the affected surface. February 18, patient had been delirious the previous night. Temperature 103 degrees F., was reduced in one hour to 101 degrees F. by guaiacol, applied externally.

February 19, temperature 101 degrees F.

February 20 , temperature 98 degrees $\mathrm{F}$.

February 21, temperature 99 degrees F. Convalescence now seemed established and progressed rapidly, much faster than is usual in such cases.

Dr. J. E. Rhodes has kindly permitted me to mention a case similarly treated by him, in which the facial erysipelas followed an intense inflammation of the nasal mucous membrane. The temperature which reached 105.2 degrees $\mathrm{F}$. was promptly reduced. On one occasion profuse perspiration and marked alleviation of the symptoms immediately followed the application. This case ran its course in one week.

The chief points of interest in these cases are:

1. The short time that elapsed between the application and the resulting relief.

2. Repeated trials on the fourth case showed that a chill could be aborted by the external application of guaiacol.

3. Except in cases of extreme irritability of the skin, the application of pure guaiacol does not cause pain. In such cases the guaiacol may be diluted with alcohol, olive or any of the fixed oils to the desired strength.

4. The amount of guaiacol employed varied from 20 to 30 minims.

5. As might be expected, such a powerful effect was not without its drawbacks. In two cases I found a subnormal temperature. These figures suggest their own caution.

The action of guaiacol in controlling chills and fever, as in Case 4, I am inclined to believe is due to an anesthetic action on peripheral nerve endings. Absorption by a skin the seat of inflammatory changes is necessarily slow, and could not account for the immediate fall of temperature noticed in these cases. Experiments have demonstrated that the temperature is not affected in animals if the site of the application is previously anesthetized. Guinard bathed the hind limbs of two rabbits with guaiacol ; in one, the sciatic nerve was cut four days before. Here the application caused no fall in temperature, while with the rabbit with nerves intact, the same fall was observed as before.

The same author in the Province Medicale for February 17, states: That if the parts are enveloped after the application, in two or three hours guaiacol may be found in the urine; and has drawn the following conclusion from his experiments: That guaiacol can penetrate through the epidermis; that this penetration appears to be the result of an absorption of the vapor; that the envelopment of the painted regions - thus keeping the vapor in contact with the skin-increases the proportion of guaiacol in the urine.

Dr. E. F. Ingals informs me that after my report to 
him of the beneficial effects of guaiacol in erysipelas, he applied it in two cases of erysipelatous inflammation of the face associated with rhinitis; and in both cases succeeded in reducing the inflammation speedily.

I have for six months been using guaiacol locally to relieve the dermatitis of the arm, following vaccination, in which I found marked constitutional symptoms. These were generally relieved by one or two th applications of 15 or 20 minims.

In regard to its action on the course of the disease, I am not prepared to state positively. In all cases convalescence began not later than the sixth day, although the disease was very extensive in three cases. Albumen was found in the urine of only one patient. Delirium was present in two cases. I am therefore inclined to believe that convalescence was somewhat hastened in all these cases.

After having treated numerous cases by the various methods advocated by different authors, I believe guaiacol to be the most efficient therapentic agent that we possess at the present time. It is certainly preferable to any of the so-called antipyretics and anodynes usually used to reduce fever or to control pain.

36 Washington Street.

\section{CLINICAL HISTORY OF THE CASE OF PRESI- DENT JAMES ABRAM GARFIELD.}

BY ROBERT REYBURN, A.M., M.D.

PROFESSOR OF PHYSIOLOGY AND CLINICAL SURGERY MEDICAL DEPART. MENT HOWARD UNIVERSITY, WASHINGTON, D. C., AND ONE OF THE ATTENDING SURGEONS IN THE CASE OF PRESIDENT GARFIELD. (Continued from page 582).

The President was more restless than usual last night being evidently excited by the anticipation of the journey. This morning at 5:30 A.m. his temperature was 99.8 ; pulse 118 ; respirations 18.

September 6 at 6 A.m. the President was tenderly lifted by the devoted friends, who had nursed him through his long and weary illness, and in company with his physicians, he was carried on a stretcher to the outer vestibule of the White House. Twice while being carried he waved his hand in recognition to those of his household he was leaving behind. The bed he had just left had preceded him. He was immediately placed upon it without the least apparent discomfort. The President seemingly enjoyed the proceedings until the car was reached. The hour was fortunately too early for any great congregation of people, yet many who had heard of his intended removal were present on the streets. In perfect silence with men guarding the heads of the horses (which by the way, were not attached until the President was safely in the wagon and were detached the moment the car was reached), we slowly wended our way to the waiting train. Twelve soldiers grasped the wheels of the wagon, as the horses were detached, and rolled it to the car containing the bed, to which the President was then transferred without the slightest disturbance. We left Washington with the President at $6: 30$ A.M. Owing to the admirable arrangements of the Pennsylvania Railroad Company, and to the ingeniously arranged bed designed by Mr. T. N. Ely for the use of the President, he suffered comparatively little and bore the fatigue of

Entered according to Act of Congress, May 29, 1893, by RoBERT REYBURN, M.D. the journey remarkably well. During the journey his temperature and pulse were taken occasionally, and the effect was noted of the varying rates of speed upon the comfort of our patient. The minimum of unpleasant motion seemed to be secured when the train was going at the rate of sixty miles per hour. Through that long hot afternoon no sound of bell or steam whistle was heard either from our own, or from the large number of trains we passed. It was indeed a strange and affecting journey, and as we silently sped along it almost seemed as if we were being transported by some invisible and noiseless force to our destination. At every station we were met by silent multitudes, who with uncovered heads greeted us, but spoke not a word. The car assigned for the use of the party contained besides the President, Mrs. and Miss Garfield, Mrs. Rockwell and Miss Rockwell, Mrs. Dr. Edson, Professor Agnew, Dr. Bliss, Surgeon-General Barnes, Dr. Woodward, Dr. Reyburn, General Swaim, Colonel Corbin, Colonel Rockwell, Secretary Brown and the two family servants.

The President seemed to enjoy the rapidity of the motion, and when the train was going at its greatest speed of over sixty miles an hour and he was asked if the motion was uncomfortable, he smiled and said: "Let them go." During the last hour of his journey he showed symptoms of exhaustion, which would have prevented his makiug any longer journey, had such been required to reach his destination.

The train reached Elberon at 1.09 P.M. A temporary railroad track had been laid from the railroad station at Elberon to the Francklyn Cottage which had been generously placed at the disposal of the President by Mr. Francklyn. On reaching the steep grade near the cottage the cars were detached from the engine and pushed by hand to the side entrance of the cottage, and from thence he was carried to the room in which he passed the remaining days of his life.

September $6,6: 30$ P.M. During the last hour of the journey the President complained a good deal of fatigue, and after his arrival was feverish and rest. less. At present his temperature is 101.6 ; pulse 124 ; respirations 18.

September 6, 10:30 P.M. The President is sleeping quietly, and his fever which was evidently due to the exhaustion resulting from his journey, is gradually subsiding.

September 7, 9 A.M. The President slept the greater part of the night, awakening, however, as often as it was necessary to give him nourishment, which he took and relished very well. The fever reported in last night's bulletin had subsided by 11 P.M. This morning his temperature is normal, and he appears to have quite recovered from the fatigue of yesterday's journey. At the morning dressing the parotid abscess was found to be doing well. The visible part of the wound looks somewhat better.

September 7,9 A.m. Temperature 98.4 ; pulse 106 ; respirations 18. September 7,6 P.M. Temperature 101; pulse 108; respirations 18.

The sight of the ocean seemed to give the President great delight. He said to those about him, "it was refreshing to get where he could look at the sea." The room where he was placed is large and handsomely furnished. When the President was taken in to the room he at once noticed that his bed was so situated that he could not look out at the sea. $\mathrm{He}$ immediately insisted that a change should be made 